\title{
Swimming speeds of larval coral reef fishes: impacts on self-recruitment and dispersal
}

\author{
Rebecca Fisher* \\ Department of Marine Biology, James Cook University, Townsville, Queensland 4811, Australia \\ Present address: National Marine Fisheries Service, Santa Cruz Laboratory, 110 Shaffer Road, Santa Cruz, \\ California 95060, USA
}

\begin{abstract}
The dispersal of larvae during their time in the pelagic environment is critically important to our understanding of marine populations. Recent publications have highlighted the potential importance of larval behaviour in influencing dispersal patterns of larval reef fishes. However, it has not been clearly established if their abilities are of a magnitude comparable to the potential effects of oceanic processes and whether larval behaviour is sufficient to facilitate self-recruitment. This study presents new data on the swimming speed of late-stage larvae to determine how they can swim relative to oceanic currents. The families examined comprised the Acanthuridae, Siganidae, Lutjanidae, Lethrinidae, Pomacentridae, Chaetodontidae, Nemipteridae, Monacanthidae, Psuedochromidae, Pomacanthidae and Apogonidae. The late-stage larvae of all reef fish families examined were able to swim at speeds greater than the mean transport speeds reported around reefs in most locations. However, even the best-swimming reef fish families could not swim faster than the maximum current speeds reported. Based on new and previously published data it appears that the development of swimming ability can be described adequately ( $80 \%$ of variation explained) as a linear increase from zero at hatching to a species-specific maximum at settlement. Calculations based on this developmental pattern suggest that most reef fish families could substantially influence their dispersal patterns relative to ocean currents for over $50 \%$ of their larval phase. For all families examined, swimming behaviour could potentially affect dispersal patterns on a magnitude similar to the dispersing effect of oceanic currents. In addition, the swimming capabilities of several reef fish families have the potential to facilitate active self-recruitment in a range of reef systems.
\end{abstract}

KEY WORDS: Swimming speed $\cdot$ Reef fish $\cdot$ Larvae $\cdot$ Dispersal $\cdot$ Settlement $\cdot$ Recruitment

\section{INTRODUCTION}

The extent of dispersal during their larval phase has implications for the population dynamics of marine organisms, potentially affecting genetic connectivity (Doherty et al. 1995), levels of self-recruitment (Cowen et al. 2000), and adult population dynamics (Doherty \& Williams 1988). In addition, knowledge of dispersal patterns is essential for designing zoning plans and fisheries management (Botsford et al. 2001). Several studies have recently demonstrated high levels of self-recruitment for some coral reef fish populations (e.g. Jones et al. 1999, Swearer et al. 1999) and it appears that limited dispersal may be a widespread phenomenon in marine populations in general (Swearer et al. 2002). Although some studies show that reduced dispersal distances may occur through oceanic processes (e.g. James et al. 2002), it is still unclear to what extent larval swimming behaviour may also influence dispersal distances in reef fish populations. Over the last $10 \mathrm{yr}$, the swimming abilities of tropical reef fish larvae have received considerable attention (reviewed in Leis \& McCormick 2002). It is now clear that many of these larvae can sustain swimming activity for considerable lengths of time (up to $271 \mathrm{~h}$; Stobutzki \& Bellwood 1997) and show fast swimming speeds (up to $60 \mathrm{~cm} \mathrm{~s}^{-1}$; Leis \& Carson-Ewart 1997). 
However, the extent to which behaviour may influence dispersal patterns relative to oceanic processes remains controversial (Roberts 1998, Bellwood et al. 1998, Sale \& Cowen 1998, Mora \& Sale 2002).

In order to determine the potential importance of swimming behaviour, it is necessary to have information on the maximum swimming abilities of larvae, how these change throughout the entire pelagic phase, and how they relate to the undisturbed sustainable swimming speeds of larvae. With this information it is possible to calculate the potential distances that larvae can swim based on realistic sustainable swimming speeds, throughout their larval phase rather than just at settlement (see Stobutzki \& Bellwood 1997). U-crit (maximum sustainable swimming speed, following Brett 1964) provides a useful maximal performance estimate of swimming speed of larvae, and it has been shown larvae can maintain swimming at speeds of $50 \% U$-crit

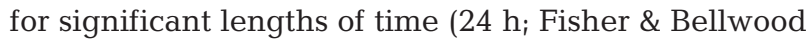
2002, Fisher \& Wilson 2004). Furthermore, $19 \% U$-crit appears to be a good approximation of the undisturbed swimming speeds of larvae during the day (Fisher \& Bellwood 2003). Maximum swimming-speed measurements have only been examined in a small number of reef fish species (Stobutzki \& Bellwood 1994, Fisher et al. 2000). There is also little information on the rate of development of maximum swimming ability during the pelagic phase (3 species from 2 families; Fisher et al. 2000). Indeed, the few models of larval dispersal that incorporate behaviour have assumed that larvae will only swim actively in the last portion of the larval phase (Wolanski et al. 1997, Armsworth et al. 2001, James et al. 2002). Testing this assumption is critically important to fully understand the potential impact that swimming behaviour can have on dispersal patterns of reef fish larvae.

In this study, I examine the swimming abilities of reef fish larvae at settlement, at hatching and throughout their pelagic phase, to assess the extent to which horizontal swimming capabilities may be used to influence their dispersal patterns. The specific objectives are to: (1) present new data on the swimming speeds of late-stage larvae and larvae at hatching in a range of families, (2) derive a model to describe the development of swimming abilities across families, and (3) use this information to predict the potential distance larvae can swim throughout their larval phase. Although I am unable to determine if directed swimming behaviour occurs and/or if larvae have the necessary sensory capabilities to execute this behaviour in a directional context in the field, this paper quantifies the magnitude of this effect on dispersal trajectories, thereby establishing the extent to which horizontal swimming behaviour may be used to influence the possible dispersal distances of these larvae.

\section{MATERIALS AND METHODS}

Maximum swimming speeds of late-stage larvae. Late-stage larval reef fishes were collected from Lizard Island, Australia, using light traps over 2 summer sampling seasons (November to December, 2000 and 2001). Light traps catch predominantly late-stage larvae, generally considered ready to settle onto a reef (Choat et al. 1993). Larvae of as many species as possible were used for swimming experiments, although no more than 10 individuals of any 1 species were used. Only families for which swimming data was obtained from at least 5 individuals were included in analyses. Larvae were used in swimming experiments at Lizard Island Research Station within $12 \mathrm{~h}$ of capture, utilising several different swimming flumes (with different maximum flow capacities to allow for different-sized larvae) similar in design to those of Stobutzki \& Bellwood (1997). Experimental protocol followed Bellwood \& Fisher (2001), with velocity increments equivalent to approximately 3 body lengths $\mathrm{s}^{-1}$ with a time interval of $2 \mathrm{~min}$. The critical swimming speed ( $U$-crit) of larvae was calculated as: $U$-crit $=U+\left(t / t_{\mathrm{i}} \times U_{\mathrm{i}}\right)$, where $U$ is the penultimate speed, $U_{\mathrm{i}}$ is the velocity increment, $t$ is the time swum in the final velocity increment and $t_{\mathrm{i}}$ is the time interval for each velocity increment. Average $U$ crit swimming speed was plotted for each family and compared to mean transport speeds around reefs, extracted from data presented in published papers.

Maximum swimming speeds of larvae at hatching. Unhatched eggs of 10 different species (Pomacentrus amboinensis, P. mollucensis, Chromis viridis, Abudefduf sexfasciatus, Amphiprion melanopus, A. percula, Acanthurus nigrofuscus, Salarius patzneri, Sphaeramia nematoptera and Apogon compressus) were obtained from a variety of different breeding parents from the reefs around Lizard Island as well as from captive breeding pairs at the James Cook University research aquarium. Eggs from demersal spawning species (Pomacentridae and Blennidae) were obtained by removing the substrate on which they were laid or by gently scraping the eggs off the substrate with a sharp knife. Eggs were obtained from oral brooders (Apogonidae) by gently catching the adult using the anaesthetic clove oil. Eggs were obtained from pelagic spawners (Acanthuridae) by watching adult behaviour in the field using SCUBA and collecting the eggs using a $32 \mu \mathrm{m}$ net immediately following release. Eggs were hatched overnight in laboratory aquariums and were used for swimming experiments on the day immediately after hatching (Day 1) following the young larvae protocol of Fisher et al. (2000).

Development of swimming abilities. Using empirical data, 2 simple models were examined and compared in terms of their ability to successfully characterise the de- 
velopment of maximum swimming speeds of larval reef fishes throughout their pelagic phase. Data were obtained from larvae reared at James Cook University and in the field at the Lizard Island Research Station, following the methods of Fisher et al. (2000). Data for 3 species are directly from Fisher et al. (2000; Pomacentrus amboinensis, Amphiprion melanopus and Sphaeramia nematoptera). Data for an additional 3 species have since been obtained ( $P$. moluccensis, Amphiprion percula and Apogon compressus). Both models are based on the assumption that swimming ability $(S)$ develops as a function of age or total length (size) to a species-specific maximum at settlement. Both age and length can be used as a measure of ontogenetic development in fishes, although better relationships are often found using length (Fuiman et al. 1998). Model 1 assumes that development starts from some speciesspecific speed, age and size at hatching $(S=$ speed speed at hatching, age = time since hatching, TL = size - size at hatching), whereas Model 2 assumes that swimming ability develops continuously from fertilisation $(S=$ speed, age $=$ time since fertilisation, $\mathrm{TL}=$ size $)$. Both models can be normalised, normalising age and length to a species-specific value at settlement. For Model 1: $A_{\mathrm{n}}=$ age (time since hatching)/age (time since hatching) at settlement, $\mathrm{TL}_{\mathrm{n}}=(\mathrm{TL}-\mathrm{TL}$ at hatching $) /$ (TL at settlement - TL at hatching); for Model 2: $A_{\mathrm{n}}=$ age (time since fertilisation)/age (time since fertilisation) at settlement, $\mathrm{TL}_{\mathrm{n}}=\mathrm{TL} / \mathrm{TL}$ at settlement), and swimming speed can be normalised to a species-specific speed at settlement. For Model 1: $S_{\mathrm{n}}=$ (speed speed at hatching)/(speed at settlement - speed at hatching); for Model 2: $S_{\mathrm{n}}=$ speed/speed at settlement). In addition, because the developmental scale is multiplicative (1 d represents more developmental change early than it does later), all values were converted to a log scale before normalisation. Such a normalisation yields a predicted relationship between $A_{\mathrm{n}}$ and $S_{\mathrm{n}}$ that is $1: 1$. Based on this predicted relationship, $\mathrm{R}^{2}$ values and residual plots were used to assess the adequacy of the fit of both models to the empirical data and an F-ratio was used to determine if either model was a significantly better fit. F-ratios were also used to determine if there were any significant differences in the fit of each model among different species, or among different families and subfamilies.

The best-fit model was Model 1 and the best relationship was with total length, rather than age. Using Model 1, swimming speed at size $(x)$ can be calculated as: $S_{(x)}=\left[10^{\mathrm{TL}}(\mathrm{x}) \cdot \log _{10}\left(S_{\text {sett }}-S_{\text {hatc }}\right)\right]+S_{\text {hatc }}$, where $S_{(x)}$ is the swimming ability at size $(x)$ in $\mathrm{cm} \mathrm{s}^{-1}, \mathrm{TL}_{\mathrm{n}(x)}$ is the normalised size at size $(x)\left[\log _{10}\left(\mathrm{TL}_{X}-\mathrm{TL}\right.\right.$ hatc $) / \log _{10}$ $\left.\left(\mathrm{TL}_{\text {sett }}-\mathrm{TL}_{\mathrm{hatc}}\right)\right], S_{\text {sett }}$ is the species-specific swimming ability at settlement in $\mathrm{cm} \mathrm{s}^{-1}, S_{\text {hatc }}$ is the speciesspecific swimming ability at hatching in $\mathrm{cm} \mathrm{s}^{-1}, \mathrm{TL}_{\text {sett }}$ is size at settlement in $\mathrm{mm}$ and $\mathrm{TL}_{\text {hatc }}$ is the speciesspecific size at hatching in $\mathrm{mm}$. This calculation was used to predict the rate of development of swimming ability in 11 reef fish families. Average swimming speeds of the late-stage larvae for each family collected in this study were used as the swimming ability of each family at settlement $\left(S_{\text {sett }}\right)$. Because individual growth data were not available for larvae of these families, growth rates were estimated from $\mathrm{TL}_{\text {sett, }} \mathrm{TL}_{\text {hatc }}$ and larval duration, assuming that growth is linear throughout the pelagic phase. Values for $S_{\text {hatc }}$ were estimated from the empirical relationship between swimming speed at hatching and size at hatching (see Fig. 2). Values for egg and larval durations, and $\mathrm{TL}_{\mathrm{hatc}}$ were obtained from numerous published sources (Bryan \& Madraisau 1977, Brothers et al. 1983, Thresher et al. 1989, Wellington \& Victor 1989, Doherty et al. 1995, Kerrigan 1996, Leis et al. 1996, Leis \& Carson-Ewart 1997, Wilson \& McCormick 1997, 1999, Stobutzki \& Bellwood 1998, McCormick 1999, Victor \& Wellington 2000, Wellington \& Robertson 2001, Gill 2002, Zapata \& Herron 2002). If more than 1 estimate of larval duration, TL hatc or egg duration was available for the same species, these were averaged. An overall average across all species was used as the mean for each family. Because the mean transport speed around Lizard Island $\left(13.5 \mathrm{~cm} \mathrm{~s}^{-1}\right.$, Frith et al. 1986) represents the mid-point in the range of speeds reported for various coral reefs around the world (see Fig. 1), the age at which larvae could swim at $13.5 \mathrm{~cm} \mathrm{~s}^{-1}$ was determined. This age was used to estimate the time during the larval phase each family could potentially begin to utilise horizontal swimming behaviour to influence dispersal patterns by swimming directly against ocean currents.

Potential distance swum and distance transported. Predicted swimming speeds for each day of development were used to calculate the potential distance larvae could swim throughout their larval phase. Recent work on undisturbed swimming behaviour suggests that larvae consistently maintain swimming speeds of approximately $19 \%$ of their average $U$-crit speed during the day and about $35 \%$ of their $U$-crit at night (Fisher \& Bellwood 2003). In addition, larvae from these families do not swim at night until they reach last $20 \%$ of their pelagic phase (Fisher \& Bellwood 2003). In these calculations I have assumed that larvae will swim during the day throughout development at a speed of $19 \%$ of their $U$-crit and at night at a speed of $35 \%$ of their $U$-crit. I re-analysed the data from Fig. 3 of Fisher \& Bellwood (2003) and obtained 95\% confidence limits of this value to estimate the potential variance in total distance swum. In addition, I re-analysed the data from their Fig. 4 and found a strong $\left(R^{2}=0.90\right)$ positive exponential relationship: Time spent active $=$ $\mathrm{e}^{4.17 \cdot(\text { developmental age) }}$, where developmental age $=$ age 
(time since fertilisation)/age (time since fertilisation) at settlement. This empirical relationship was used to calculate the time larvae spend swimming actively at night, and variance (95\% confidence limits) associated with this relationship was also incorporated into variance estimates of distance swum. Other potential sources of variance also included (in the form of $95 \%$ confidence limits for each parameter) were size at settlement, speed at settlement and the error associated with estimating swimming speed at hatching using the relationship shown for total length (see Fig. 2). Implicit in the calculations is the assumption that pelagically spawned eggs float passively until hatching.

To compare the magnitude of the potential swimming distance of larvae to the effects of oceanic currents, estimates of total distance swum throughout development for each family were plotted against distance transported. Transport distances were obtained from Frith et al. (1986) for around Lizard Island, but are in the range reported in other studies (see Roberts 1997, James et al. 2002) and provide a benchmark for comparing the effect of behaviour relative to oceanic processes. Clearly, there is a large degree of spatio-

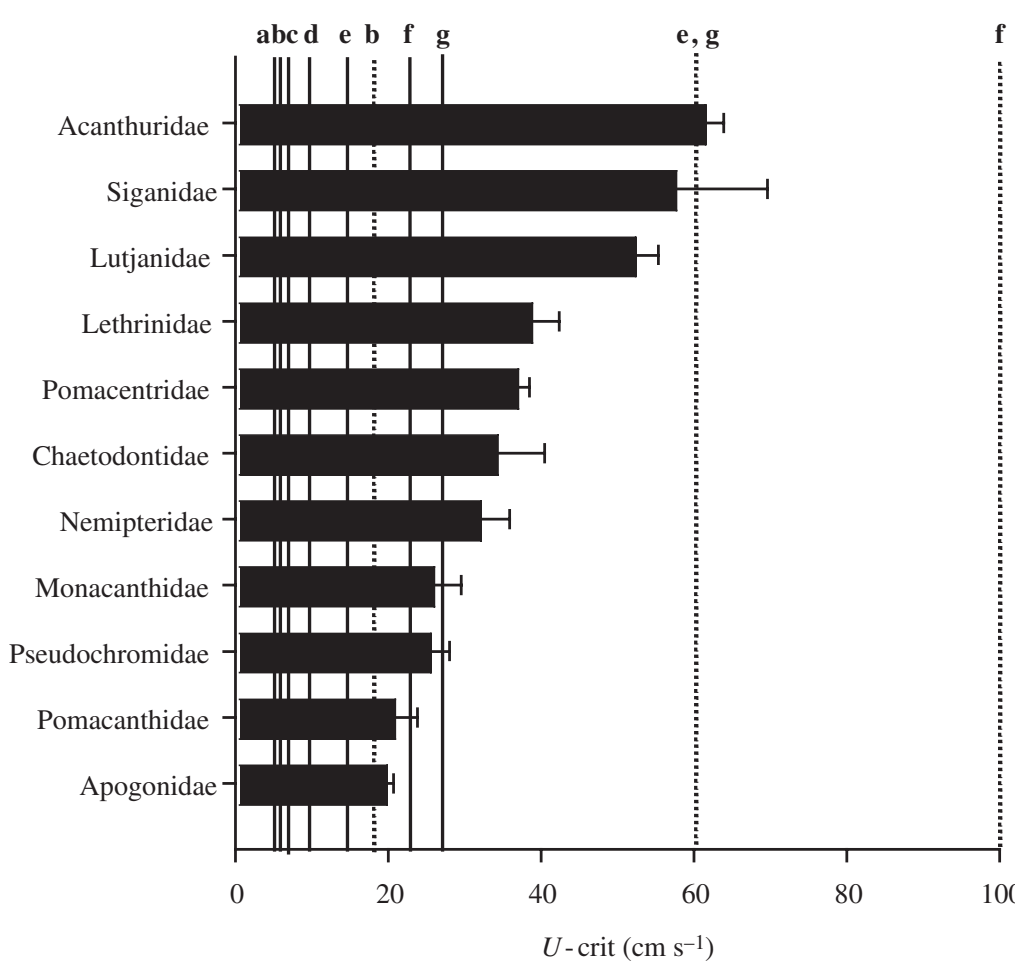

Fig. 1. Average (+SE) swimming speed (U-crit) of late-stage larvae from 11 families of reef fish from Lizard Island, Australia. Continuous lines: mean transport speeds reported by researchers in various locations around world; a: Florida Keys (Pitts 1994); b: Bahamas (Thorrold et al. 1994); c: GBR (Hamner \& Hauri 1981); d: GBR (Andrews 1983); e: Lizard Island, GBR (Frith et al. 1986); f: Barbados (Cowen \& Castro 1994); g: GBR (Wolanski \& Pickard 1983). Dotted lines: maximum speeds reported temporal variation in current speeds observed around reefs; this comparison merely aims at comparing the relative importance of swimming behaviour and the median effect of oceanic currents.

\section{RESULTS}

The maximum swimming speeds of late-stage reef fish larvae varied considerably among families (Fig. 1). However, all families measured were able to swim faster than mean transport speeds in the Bahamas (Thorrold et al. 1994), Florida Keys (Pitts 1994) as well as the lower estimates of mean transport speeds on the Great Barrier Reef (GBR) (Hamner \& Hauri 1981, Andrews 1983, Frith et al. 1986). The late-pelagicstage larvae of all 11 families of reef fishes could swim at speeds greater than $13.5 \mathrm{~cm} \mathrm{~s}^{-1}$, which is the mean transport speed around Lizard Island (Frith et al. 1986) and represents a good mid-point among the range reported for average current speeds around coral reefs in general (Fig. 1). Of the families examined, 7 , comprising the Acanthuridae, Siganidae, Lutjanidae, Lethrinidae, Pomacentridae, Chaetodontidae and Nemipteridae were able to swim faster than the upper estimates of mean transport speeds worldwide (Fig. 1). No families of reef fishes were capable of swimming against the maximum current speeds reported (100 $\mathrm{cm} \mathrm{s}^{-1}$, Fig. 1).

Swimming speeds at hatching varied considerably among the species examined (Fig. 2). Significant positive relationships were found between swimming ability at hatching and both egg duration $\left(F_{1,9}=\right.$ 10.87, $\mathrm{p}=0.01)$ and size $\left(F_{1,9}=7.55, \mathrm{p}=\right.$ 0.03). The fastest-swimming larvae at hatching were the Amphiprion melanopus larvae, which also have the largest size at hatching and an extended egg duration. The slowest swimmers at hatching were the pelagically spawned Acanthurus nigrofuscus larvae, which had the shortest egg duration and also the smallest size at hatching of the species examined (Fig. 2).

A comparison of the 2 simple models for predicting the development of swimming ability throughout ontogeny suggested that a model based on a species-specific speed at hatching and at settlement (Model 1) provides a more accurate approximation of the development of swimming ability across taxa than a model based on continuous development from fertilisation (Fig. 3). While F-ratios directly comparing 
the fit of the 2 models to the empirical data indicated that neither was a significantly better fit for either age $\left(F_{37,37}=0.79, \mathrm{p}=0.76\right)$ or size $\left(F_{37,37}=0.56, \mathrm{p}=0.96\right), \mathrm{R}^{2}$ values indicated that Model 1 explained considerably greater variation in swimming ability throughout development than Model 2 for both age and size (Fig. 3). Moreover, for Model 1 there was no significant difference in the fit among species $\left(F_{37,27}=1.00, \mathrm{p}=0.49\right)$ or among taxa (Amphiprioninae, Pomacentrinae and Apogonidae; $F_{37,33}=1.16, \mathrm{p}=0.34$ ), whereas for Model 2 there was a significant difference in the fit among species $\left(F_{37,27}=1.91, \mathrm{p}=0.03\right)$ as well as among taxa $\left(F_{37,33}=\right.$ $1.82, \mathrm{p}=0.05)$. For all models there was no significant difference in the fit of the model to different species within taxa (Amphiprioninae, Pomacentrinae and Apogonidae). While not a significantly better fit $\left(F_{37,37}=\right.$ $1.41, \mathrm{p}=0.15)$, the higher $\mathrm{R}^{2}$ value $(0.92)$ and a better residual distribution among the different taxa suggests that Model 1 based on size rather than age provides a more accurate description of the development of swimming abilities throughout ontogeny across taxa (Fig. 3).

A linear fit to Model 1 was therefore used to predict developmental rates of swimming ability across a range of reef fish families: 4 families, the Apogonidae, Nemipteridae, Pomacanthidae and Pseudochromidae would be unable to swim against mean transport speeds at Lizard Island $\left(13.5 \mathrm{~cm} \mathrm{~s}^{-1}\right)$ for more than onehalf of their larval phase (Table 1); 3 families, the Acanthuridae, Lutjanidae and Siganidae, could theoretically swim against mean transport speeds around Lizard Island for $>65 \%$ of their larval phase (Table 1); the remaining 4 families, the Chaetodontidae, Lethrinidae, Monacanthidae and Pomacentridae, should be able to swim against mean transport speeds around Lizard Island for a significant portion of their larval phase (53 to $60 \%$, Table 1 ).

Based on mid-point transport distances from Lizard Island and mid-range swimming speeds, no families would be capable of self-recruiting using horizontal swimming behaviour alone, although for 3 families (Acanthuridae, Lutjanidae and Siganidae) potential distances swum are very close to the distances transported (Fig. 4), while 4 other families (Chaetodontidae, Lethrinidae, Nemipteridae and Pomacentridae) should be able to swim at least half the distances they would be transported which, given the high variability in oceanographic processes, could clearly have a substantial impact on their dispersal patterns (Fig. 4). The Apogonidae, Monacanthidae, Pomacanthidae and Pseudochromidae are the only 4 families unable to swim even half of the distance they would be transported from their natal reef. No families have the capability to actively self-recruit to Lizard Island using horizontal swimming behaviour under conditions of maximum transport (Fig. 4).
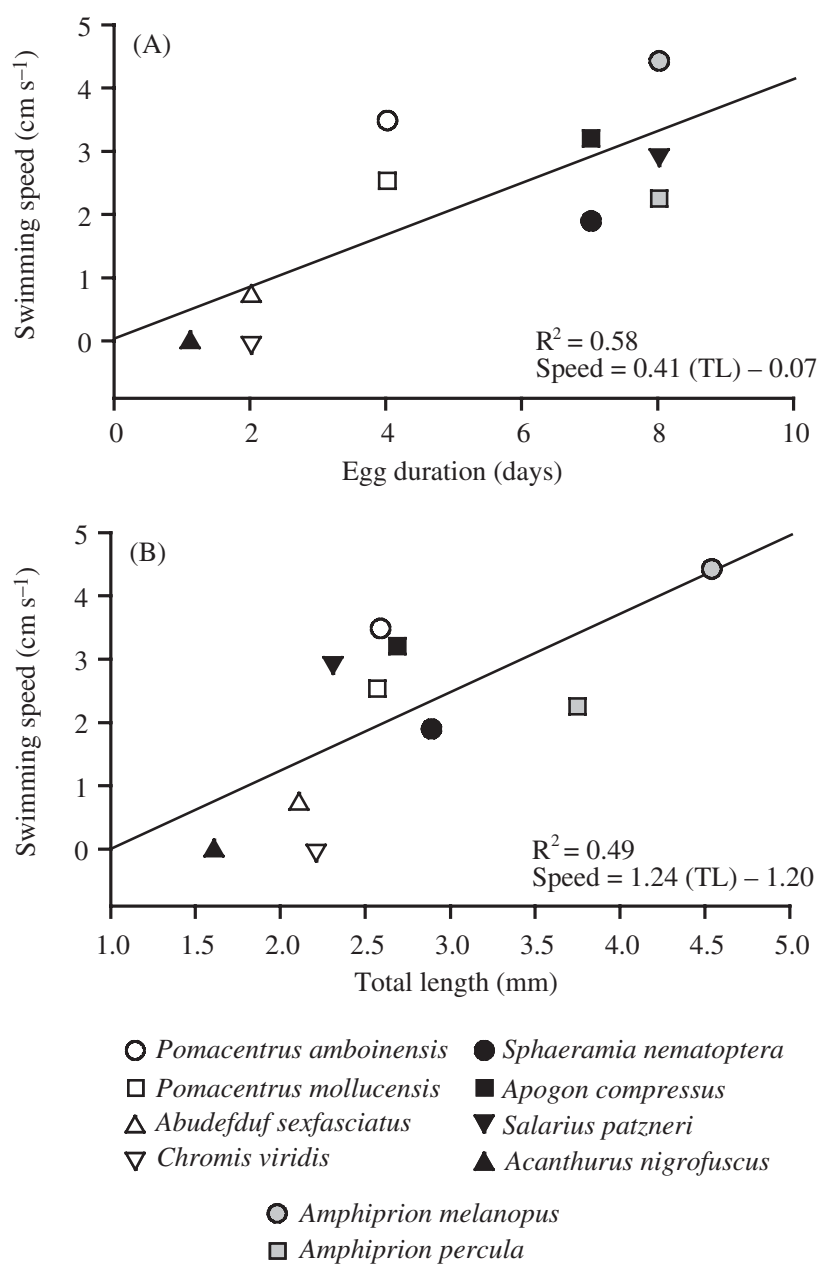

Fig. 2. Swimming speed (U-crit) at hatching as a function of (A) egg duration and (B) total length (TL) at hatching for 10 different species of coral reef fishes. Lines: fitted linear least-squares regressions

Table 1. Duration of egg development (ED), duration of larval development $(\mathrm{LD})$, size at hatching $\left(\mathrm{TL}_{\mathrm{hatc}}\right)$, size at settlement $\left(\mathrm{TL}_{\text {sett }}\right)$, and proportion of pelagic-phase larvae (PPL) capable of swimming at a speed $>13.5 \mathrm{~cm} \mathrm{~s}^{-1}$ (mean water transport speed around Lizard Island; Frith et al. 1986)

\begin{tabular}{|lccccc|}
\hline Family & $\begin{array}{c}\text { ED } \\
(\mathrm{d})\end{array}$ & $\begin{array}{c}\mathrm{LD} \\
(\mathrm{d})\end{array}$ & $\begin{array}{c}\mathrm{TL}_{\text {hatc }} \\
(\mathrm{mm})\end{array}$ & $\begin{array}{c}\mathrm{TL}_{\text {sett }} \\
(\mathrm{mm})\end{array}$ & $\begin{array}{c}\text { PPL } \\
(\%)\end{array}$ \\
\hline Acanthuridae & 1.1 & 64 & 1.7 & 29.4 & 72 \\
Apogonidae & 6.5 & 22.5 & 2.6 & 12.6 & 29 \\
Chaetodontidae & 1 & 33.6 & 1.5 & 19.8 & 54 \\
Lethrinidae & 1.6 & 35.8 & 1.6 & 21.8 & 60 \\
Lutjanidae & 0.9 & 34.2 & 2.1 & 27.7 & 69 \\
Monacanthidae & 1.2 & 24 & 2.1 & 24.8 & 58 \\
Nemipteridae & 1 & 19 & 1.6 & 17.1 & 35 \\
Pomacanthidae & 1 & 19 & 1.8 & 16.4 & 35 \\
Pomacentridae & 3.5 & 23.2 & 2.5 & 15.0 & 53 \\
Pseudochromidae & 3.5 & 27.5 & 3.4 & 17.4 & 45 \\
Siganidae & 1.1 & 32.5 & 2.4 & 28.9 & 70 \\
& & & & & \\
\hline
\end{tabular}




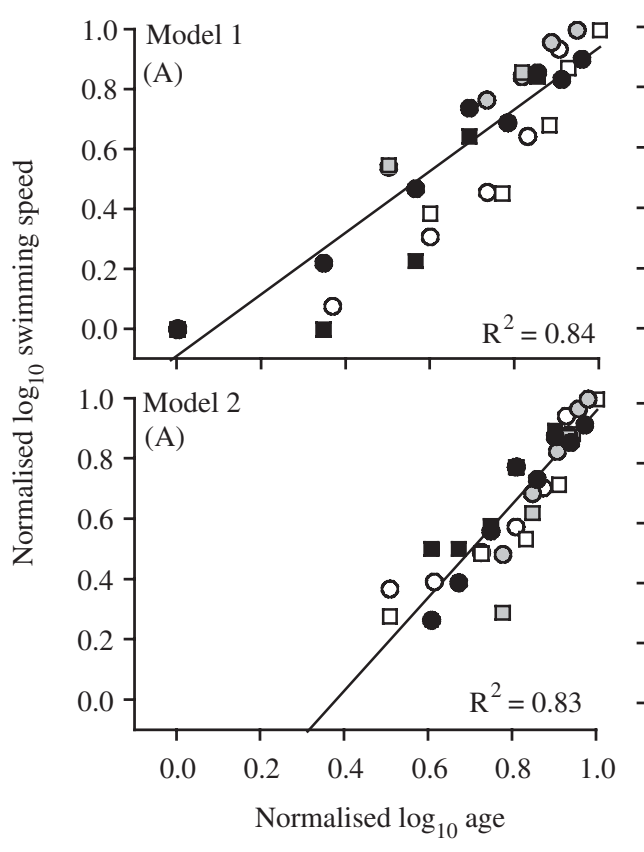

- Amphiprion melanopus

- Amphiprion percula
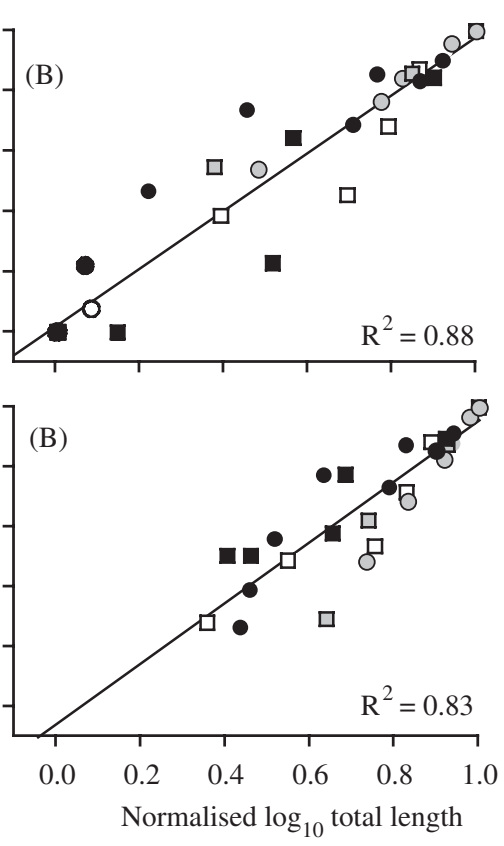

- Pomacentrus amboinensis 口 Pomacentrus moluccensis
○ Sphaeramia nematoptera 口 Apogon compressus
Fig. 3. Comparison of 2 models predicting development of swimming ability. (A) Normalised swimming speed $\left(S_{\mathrm{n}}\right)$ plotted against normalised age $\left(A_{n}\right)$; (B) normalised swimming speed $\left(S_{\mathrm{n}}\right)$ plotted against normalised total length $\left(\mathrm{TL}_{\mathrm{n}}\right)$. In Model 1: $A_{\mathrm{n}}=$ $\log _{10}$ age (time since hatching)/ $\log _{10}$ age (time since hatching) at settlement: $\mathrm{TL}_{\mathrm{n}}=\log _{10}(\mathrm{TL}-\mathrm{TL}$ at hatching) $/ \log _{10}$ (TL at settlement TL at hatching); $S_{\mathrm{n}}=\log _{10}$ (speed - speed at hatching) $/ \log _{10}$ (speed at settlement - speed at hatching). In Model 2: $A_{\mathrm{n}}=\log _{10}$ age (time since fertilisation)/ $\log _{10}$ age (time since fertilisation) at settlement; $\mathrm{TL}_{\mathrm{n}}=\log _{10} \mathrm{TL} / \log _{10} \mathrm{TL}$ at settlement); $S_{\mathrm{n}}=\log _{10}$ speed $/ \log _{10}$ speed at settlement. Lines: fitted leastsquares regressions

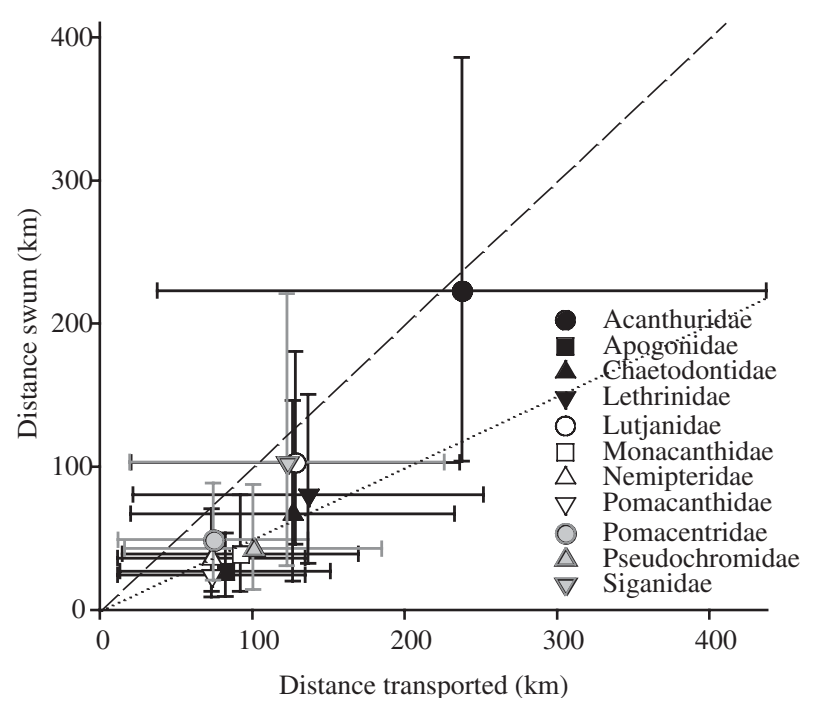

Fig. 4. Predicted distance swum versus distance transported for 11 families of reef fishes. Distance swum calculated based on Model 1, assuming larvae will swim at $19 \%$ of their average $U$-crit speed during the day throughout ontogeny and at $35 \%$ of their $U$-crit at night, following empirical relationship activity $=\mathrm{e}^{4.17 \text { (developmental age) }}$ (Fisher \& Bellwood 2003). Y-error bars were determined from lower and upper $95 \%$ confidence limits of all parameters used in calculations of distance swum. Distance transported is based on mid-point value of $25.5 \mathrm{~km}$ $\mathrm{wk}^{-1}$ and $x$-error bars represent range 4 to $47 \mathrm{~km} \mathrm{wk}^{-1}$ reported in Frith et al. (1986). Dashed line: predicted distance swum by larvae is equal to distance transported; dotted line: predicted distance swum is equal to half the distance transported

\section{DISCUSSION}

This is the first attempt to compare the swimming abilities of tropical reef fish larvae with potential transport distances based on undisturbed routine swimming abilities throughout the pelagic phase. The results demonstrate that some families are capable of swimming faster than mean transport speeds for a substantial portion of their larval phase. Furthermore, some may have the potential to swim distances comparable to their potential transport distances from reefs. Although transport distances are based on data from Lizard Island, the distances are also comparable to data from a range of reef systems. For example, James et al. (2002) suggest that larvae would be transported 21 to $43 \mathrm{~km}$ (mid-point dispersal trajectories) over $6 \mathrm{~d}$ at 4 locations on the Great Barrier Reef, which is in the range considered in this study. Roberts (1997) also reports transport distances of 145 to $219 \mathrm{~km}$ in the Caribbean, over 1 and 2 mo respectively (Roberts 1997), corresponding to a transport rate of 26 to $36 \mathrm{~km} \mathrm{wk}^{-1}$. Clearly, the swimming capabilities of larvae are of a magnitude comparable to the effect of average currents in a range of reef locations. Although the swimming speeds and distances travelled by larvae are similar to average transport speeds and distances, this is not true for maximum current speeds, which are in the order of $100 \mathrm{~cm} \mathrm{~s}^{-1}$ (Cowen \& Castro 1994). No reef fish family was able to swim at such high speeds, even nearing settlement. However, 
calculation of potential swimming distances in this study have also assumed no use of vertical or horizontal shear to maximise retention and are thus conservative estimates of the impact of larval behaviour (Armsworth 2001).

The potential for behaviourally mediated selfrecruitment in several reef fish families raises the question of whether or not such homing behaviour might actually occur. In a recent review, Strathmann et al. (2002) suggested that the advantages of long-distance dispersal of larvae are not apparent, and that broad dispersal patterns may be an incidental by-product of an ontogenetic migration from and back to the parental habitat. Furthermore, selection may even favour larval retention rather than dispersal, because the parental area must contain suitable habitat for growth and reproduction (Strathmann et al. 2002). Although modelling by Armsworth et al. (2001) indicates that a return-based strategy by larval pomacentrids and acanthurids would be unsuccessful because larvae would exhaust energy reserves before returning to the parental area, it is sensitive to the assumption that larvae do not feed (Fisher \& Bellwood 2001). This assumption is unlikely to hold for most reef fish larvae. Furthermore, a return-based strategy would be favoured even more if larvae were capable of reducing rates of advection from an early age. The results of this study suggest that many reef fish families may be able to influence their dispersal patterns as early as 30 to $70 \%$ of the way through their larval phase.

For active behaviour to be effective in influencing dispersal patterns, larvae need to have the capabilities to detect and respond to the presence of suitable habitats at a variety of scales. For coral reef fishes, recent findings have shown that larvae have well-developed sensory abilities and may have the potential to locate reefs and actively search for suitable settlement sites (see recent reviews by Montgomery et al. 2001, Kingsford et al. 2002, Leis \& McCormick 2002). On small scales, both visual (Job \& Bellwood 1996, 2000) and chemosensory (Arvedlund \& Nielsen 1996, Arvedlund et al. 1999, 2000) cues may be used for active habitat selection by settling larvae. On a larger scale, several in situ experiments have demonstrated that late-stage larvae are capable of responding to the presence of reefs at considerable distance (Leis et al. 1996, Stobutzki \& Bellwood 1998, Leis \& Carson-Ewart 1999). Long-distance detection of reef location may be possible through the use of either auditory (McCauley \& Cato 2000, Tolimieri et al. 2000) or chemical (Atema et al. 2002) cues, although the latter could only be used from down-reef locations. Other navigational cues that may be available to fishes include a magnetic compass, inertial mechanisms, sun-compass, polarised light and electric fields (Montgomery et al. 2001 and papers cited therein), all of which could provide directional cues for navigation over considerable distances.

An interesting finding is that both demersal as well as pelagic spawning species have the swimming capability to substantially influence their dispersal patterns and potentially actively self-recruit using swimming behaviour. While larvae from pelagic eggs tend to have longer larval durations and may be transported farther from shore (Leis 1993), the greater swimming capabilities generally exhibited by these species indicates that they have a similarly high potential to facilitate self-recruitment. This may explain why, in some situations, reproduction mode has little impact on small-scale (within-region) connectivity of marine populations or genetic diversity, especially when comparing different taxa (for example in the Caribbean, Shulman \& Bermingham 1995). In addition, potential self-recruiters come from families with long larval duration (e.g. Acanthuridae $\sim 64 \mathrm{~d}$ ) as well as those that have considerably shorter larval durations (e.g. Pomacentridae $\sim 20 \mathrm{~d}$ ). This could account for the generally poor relationship between the length of larval duration and species ranges for reef fishes (Victor \& Wellington 2000, Jones et al. 2002).

While many of these long pelagic-duration, broadcast-spawning species have significant potential for behaviourally-mediated self-recruitment, it is also possible they may use behaviour to actually increase rates of long-distance dispersal, a strategy that may be advantageous under some circumstances (e.g. in the presence of specialised natural enemies [MullerLandau et al. 2003] or to colonise distant locations). Depending on localised current regimes, larvae could potentially use active swimming behaviour to increase dispersal distances by a similar order of magnitude relative to their passive dispersal trajectories. While some studies suggest that larval reef fishes have relatively restricted dispersal patterns compared to what one would expect of passive particles (e.g. Doherty et al. 1995), there is evidence that long-distance dispersal does occur. Several studies have found the larvae of coral reef fishes at great distances from shore (e.g. Victor 1987) and there is a tendency for long-pelagicduration species to have greater geographic ranges at sufficiently large scales (e.g. across the Pacific; Victor \& Wellington 2000). Furthermore, several studies have found a strong significant relationship between genetic differentiation and pelagic larval duration and other early life history reproductive characteristics (Doherty et al. 1995, Riginos \& Victor 2001). It appears that while a long larval duration and a broadcastspawning reproductive mode does not necessarily preclude the use of behaviour to enhance local retention, behaviour may also be used to enhance long-distance dispersal capabilities in some species. Indeed, if larvae 
utilise horizontal swimming in a random direction, they may simultaneously facilitate local retention as well as long-distance dispersal, thereby expanding the overall dispersal kernel. A greater understanding of how swimming behaviour is utilised by different taxa with differing early life history characteristics is essential to determine the overall impact this behaviour may have on dispersal patterns.

The results reported here rely on the model used to predict swimming ability during ontogeny. Of the 2 models compared, that based on a species-specific speed at hatching and at settlement (Model 1) showed the closest correspondence to the empirical data. There were clear differences among taxa in the development of swimming abilities based on Model 2 (assuming that swimming ability develops continuously from fertilisation). While the Pomacentrinae and Apogonidae show a relatively consistent relationship, the Amphipioninae clearly have much poorer swimming abilities at hatching than would be expected if development occurred continuously from fertilisation. This suggests that the development of swimming abilities in larvae occurs at a different rate (in proportion to age as well as length) prior to hatching than during the pelagic phase.

The results presented in this paper are also sensitive to the type of swimming ability that has been measured and how this relates to undisturbed in situ behaviour. Here I have used $U$-crit (a measure of maximum swimming speed) to estimate undisturbed or routine speeds of larvae. The values used in the model were based primarily on the comparison of $U$-crit to undisturbed speed in Fisher \& Bellwood (2003), which suggested that during the day larvae swim at $19 \%$ of their maximum potential. Their experiments, however, were conducted in an enclosed environment without external stimuli and may therefore represent conservative estimates of swimming speed. Recent work suggests that speeds as high as $50 \%$ of $U$-crit are sustainable by larvae for considerable lengths of time (over 24 h) (Fisher \& Wilson 2004) and that larvae also appear to swim in situ at similarly high relative speeds (J. Leis \& R. Fisher unpubl. data). If this is true, then the impact of swimming behaviour may be considerably greater than presented here.

The ultimate impact of behaviour on the dispersal patterns of marine larvae will result from the interaction of this behaviour with prevailing oceanographic processes. Although a detailed analysis of oceanographic processes is beyond the scope of this paper, it is clear that these will vary considerably on both spatial and temporal scales (reviewed in Cowen 2002). This variation will lead to spatial and temporal variation in the relative importance of active behaviour and oceanography in shaping the dispersal patterns of reef fish larvae. There is no doubt that detailed oceanographic models will provide valuable insights into the likely dispersal trajectories of larvae (e.g. James et al. 2002). However, given that larval behaviour may have an effect similar in magnitude to that of oceanic processes, it is clear that such behaviour needs to be incorporated into models of larval dispersal. The full impact of swimming on dispersal distances can only be determined once we have a greater understanding of the behaviour exhibited by larvae in the field. Larvae may undergo vertical migration to take advantage of vertical shear, swim either with or against the direction of current flow or even shoreward, perpendicular to longshore currents. How swimming abilities are employed and the overall behaviour of larvae in the field remains a critical issue that urgently warrants further investigation. However, this study does provide the first estimates of potential horizontal swimming distances of larvae based on the development of realistic undisturbed swimming speeds and known activity patterns throughout ontogeny for several coral reef fish families, and clearly demonstrates the potential importance of this behaviour.

Acknowledgements. This work was supported by a Lizard Island Doctoral Fellowship (Australian Museum), the Australian Coral Reef Society, the Project AWARE foundation and the CRC Reef Research Centre. Thanks to M. I. McCormick, J. M. Leis, S. Simpson and O. Haine for assistance with collecting larval fishes; E. J. Dick and C. Syms for help with modelling calculations; S. Wilson, P. Hansen, H. Parks, K. Hutson, S. Golding, D. Fisher and the staff of the Lizard Island Research station for field assistance; D. R. Bellwood, S. Conolly, S. Wilson and 4 anonymous reviewers provided valuable comments on the manuscript.

\section{LITERATURE CITED}

Andrews JC (1983) Water masses, nutrient levels and seasonal drift on the outer central Queensland shelf (Great Barrier Reef). Aust J Mar Freshw Res 34:821-834

Armsworth PR (2001) Directed motion in the sea: efficient swimming over movement scales by reef fish larvae. J Theor Biol 210:81-91

Armsworth PR, James MK, Bode L (2001) When to press on or turn back: dispersal strategies for reef fish larvae. Am Nat 157:434-450

Arvedlund M, Nielsen LE (1996) Do the anemonefish Amphiprion ocellaris (Pisces: Pomacentridae) imprint themselves to their host sea anemone Heteractis magnifica (Anthozoa: Actinidae)? Ethology 102:197-211

Arvedlund M, McCormick MI, Fautin DG, Bildsoe M (1999) Host recognition and possible imprinting in the anemonefish Amphiprion melanopus (Pisces: Pomacentridae). Mar Ecol Prog Ser 188:207-218

Arvedlund M, Bundgaard I, Nielsen L (2000) Host imprinting in anemonefishes (Pisces: Pomacentridae): does it dicate spawning site preference? Environ Biol Fish 58:203-213

Atema J, Kingsford MJ, Gerlach G (2002) Larval reef fish could use odour for detection, retention and orientation to reefs. Mar Ecol Prog Ser 241:151-160 
Bellwood DR, Fisher R (2001) Relative swimming speeds in reef fish larvae. Mar Ecol Prog Ser 211:299-303

Bellwood DR, Leis JM, Stobutzki IC (1998) Fishery and reef management. Science 279:2021-2022

Botsford LW, Hastings A, Gaines SD (2001) Dependence of sustainability on the configuration of marine reserves and larval dispersal distance. Ecol Lett 4:144-150

Brett JR (1964) The respiratory metabolism and swimming performance of young sockeye salmon. J Fish Res Board Can 21:1183-1226

Brothers EB, Williams DM, Sale PF (1983) Length of larval life in twelve families of fishes at 'One Tree Lagoon', Great Barrier Reef, Australia. Mar Biol 76:319-324

Bryan PG, Madraisau BB (1977) Larval rearing and development of Siganus lineatus (Pisces: Siganidae) from hatching through metamorphosis. Aquaculture 10:243-252

Choat JH, Doherty PJ, Kerrigan BA, Leis JM (1993) A comparison of towed nets, purse seine, and light-aggregation devices for sampling larvae and pelagic juveniles of coral reef fishes. Fish Bull US 91:195-209

Cowen RK (2002) Larval dispersal and retention and consequences for population connectivity. In: Sale P (ed) Coral reef fishes; diversity and dynamics in a complex ecosystem. Academic Press, San Diego, CA, p 149-170

Cowen RK, Castro LR (1994) Relation of coral reef fish larval distributions to island scale circulation around Barbados, West Indes. Bull Mar Sci 54:228-244

Cowen RK, Lwiza KMM, Sponaguale S, Paris CB, Olsen DB (2000) Connectivity of marine populations: open or closed? Science 287:857-859

Doherty PJ, Williams DM (1988) The replenishment of coral reef fish populations. Oceanogr Mar Biol Annu Rev 26: 487-551

Doherty PJ, Planes S, Mather P (1995) Gene flow and larval duration in seven species of fish from the Great Barrier Reef. Ecology 76:2373-2391

Fisher R, Bellwood DR (2001) Effects of feeding on the sustained swimming abilities of late-stage larval Amphiprion melanopus. Coral Reefs 20:151-154

Fisher R, Bellwood DR (2002) The influence of swimming speed on sustained swimming performance of late-stage reef fish larvae. Mar Biol 140:801-807

Fisher R, Bellwood DR (2003) Undisturbed swimming behaviour and nocturnal activity of coral reef fish larvae. Mar Ecol Prog Ser 262:177-188

Fisher R, Wilson SK (2004) Maximum swimming speeds of nine species of late-stage larval reef fishes. J Exp Mar Biol Ecol 312:171-186

Fisher R, Bellwood DR, Job SD (2000) The development of swimming abilities in reef fish larvae. Mar Ecol Prog Ser 202:163-173

Frith CA, Leis JM, Goldman B (1986) Currents in the Lizard Island region of the Great Barrier Reef Lagoon and their relevance to potential movements of larvae. Coral Reefs 5: 81-92

Fuiman LA, Poling KR, Higgs DM (1998) Quantifying developmental progress for comparative studies of larval fishes. Copeia 1998:602-611

Gill AT (2002) Revision of the Indo-Pacific dottyback fish subfamily Pseudochrominae (Perciformes: Pseudochromidae). Ichthyol Monogr S Afr Inst Aquat Biodivers 1:1-230

Hamner WM, Hauri IR (1981) Effects of island mass: water flow and plankton pattern around a reef in the Great Barrier Reef Lagoon, Australia. Limnol Oceanogr 26: 1084-1102

James MK, Armsworth PR, Mason LB, Bode L (2002) The structure of reef fish metapopulations: modelling larval dispersal and retention patterns. Proc Soc Lond Ser B 269: 2079-2086

Job S, Bellwood D (1996) Visual acuity and feeding in larval Premnas biaculeatus. J Fish Biol 48:952-963

Job S, Bellwood D (2000) Light sensitivity in larval fishes: implications for vertical zonation in the pelagic zone. Limnol Oceanogr 45:362-371

Jones GP, Milicich MJ, Emlie MJ, Lunow C (1999) Self recruitment in a coral reef fish population. Nature 402: 802-804

Jones GP, Caley MJ, Munday PL (2002) Rarity in coral reef fish communities. In: Sale PF (ed) Coral reef fishes; dynamics and diversity in a complex ecosystem. Academic Press, San Diego, CA, p 81-102

Kerrigan BA (1996) Temporal patterns in size and condition at settlement in two tropical reef fishes (Pomacentridae: Pomacentrus ambionensis and P. nagasakiensis). Mar Ecol Prog Ser 135:27-41

Kingsford MJ, Leis JM, Shanks A, Lindeman K, Morgan S, Pineda PJ (2002) Sensory environments, larval abilities and local self-recruitment. Bull Mar Sci 70:309-340

Leis JM (1993) Larval fish assemblages near Indo-Pacific coral reefs. Bull Mar Sci 53:362-392

Leis JM, Carson-Ewart BM (1997) In situ swimming speeds of the late pelagic larvae of some Indo-Pacific coral reef fishes. Mar Ecol Prog Ser 159:165-174

Leis JM, Carson-Ewart BM (1999) In situ swimming and settlement behaviour of larvae of an Indo-Pacific coral reef fish, the coral trout Plectropomus leopardus (Pisces: Serranidae). Mar Biol 134:51-64

Leis J, McCormick M (2002) The biology, behaviour, and ecology of the pelagic, larval stage of coral reef fishes. In: Sale P (ed) Coral reef fishes; dynamics and diversity in a complex ecosystem. Academic Press, San Diego, CA, p 171-200

Leis JM, Sweatman HPA, Reader SE (1996) What the pelagic stages of coral reef fishes are doing out in blue water: daytime field observations of larval behavioural capabilities. J Mar Freshw Res 47:401-411

McCauley RD, Cato DH (2000) Patterns of fish calling in a nearshore environment in the Great Barrier Reef. Phil Trans R Soc Lond B 355:1289-1293

McCormick MI (1999) Delayed metamorphosis of a tropical reef fish (Acanthurus triostegus): a field experiment. Mar Ecol Prog Ser 176:25-38

Montgomery J, Tolimieri N, Haine O (2001) Active habitat selection by pre-settlement reef fishes. Fish Fish Ser 2: 261-277

Mora C, Sale PF (2002) Are populations of reef fish open or closed? Trends Ecol Evol 17:422-426

Muller-Landau HC, Levin SA, Keymer JE (2003) Theoretical perspectives on evolution of long-distance dispersal and the example of specialised pests. Ecology 84:1957-1967

Pitts PA (1984) An investigation of near-bottom flow patterns along and across Hawk Channel, Florida Keys. Bull Mar Sci 54:610-620

Riginos C, Victor BC (2001) Larval spatial distributions and other early life-history characteristics predict genetic differentiation in eastern Pacific blennioid fishes. Proc R Soc Lond Ser B 268:1931-1936

Roberts CM (1997) Connectivity and management of Caribbean coral reefs. Science 278:1454-1457

Roberts CM (1998) Fishery and reef management. Science 279:2022-2023

Sale PF, Cowen RK (1998) Fishery and reef management. Science 279:2022

Shulman MJ, Bermingham E (1995) Early life histories, ocean 
currents, and the population genetics of Caribbean reef fishes. Evolution 49:897-910

Stobutzki IC, Bellwood DR (1994) An analysis of the sustained swimming abilities of pre- and post-settlement coral reef fishes. J Exp Biol Ecol 175:275-286

Stobutzki IC, Bellwood DR (1997) Sustained swimming abilities of the late pelagic stages of coral reef fishes. Mar Ecol Prog Ser 149:35-41

Stobutzki IC, Bellwood DR (1998) Nocturnal orientation to reefs by late pelagic stage coral reef fishes. Coral Reefs 17 : 103-110

Strathmann RR, Hughes TP, Kuris AM, Lindeman KC, Morgan SG, Pandolfi JM, Warner RR (2002) Evolution of local recruitment and its consequences for marine populations. Bull Mar Sci 70:377-396

Swearer SE, Caselle JE, Lea DW, Warner RR (1999) Larval retention and recruitment in an island population of a coral-reef fish. Nature 402:799-802

Swearer SE, Shima JS, Hellberg ME, Thorrold SR and 6 others (2002) Evidence of self-recruitment in demersal marine populations. Bull Mar Sci 70:251-271

Thorrold SR, Shenker JM, Mojica R, Maddox ED, Wishinski E (1994) Temporal patterns in the larval supply of summerrecruiting reef fishes to Lee Stocking Island, Bahamas. Mar Ecol Prog Ser 112:75-86

Thresher RE, Colin PL, Bell LJ (1989) Planktonic duration, distribution and population structure of western and central Pacific Damselfishes (Pomacentridae). Copeia 1989: 420-434

Tolimieri N, Jeffs A, Montgomery JC (2000) Ambient sound

Editorial responsibility: Charles Birkeland (Contributing Editor), Honolulu, Hawaii, USA as a cue for navigation by the pelagic larvae of reef fishes. Mar Ecol Prog Ser 207:219-224

Victor BC (1987) Growth, dispersal, and identification of planktonic labrid and pomacentrid reef-fish larvae in the eastern Pacific Ocean. Mar Biol 95:145-152

Victor BC, Wellington GM (2000) Endemism and the pelagic larval duration of reef fishes in the eastern Pacific Ocean. Mar Ecol Prog Ser 205:241-248

Wellington GM, Robertson DR (2001) Variation in larval life history traits among reef fishes across the Isthmus of Panama. Mar Biol 138:11-22

Wellington GM, Victor BC (1989) Planktonic larval duration of one hundred species of Pacific and Atlantic damselfishes (Pomacentridae). Mar Biol 101:557-567

Wilson DT, McCormick MI (1997) Spatial and temporal validation of settlement-marks in the otoliths of tropical reef fishes. Mar Ecol Prog Ser 153:259-271

Wilson DT, McCormick MI (1999) Microstructure of settlement-marks in the otoliths of tropical reef fishes. Mar Biol 134:29-41

Wolanski E, Pickard GL (1983) Upwelling by internal tides and Kelvin waves at the continental shelf break on the Great Barrier Reef. Aust J Mar Freshw Res 34:65-80

Wolanski E, Doherty PJ, Carleton J (1997) Directional swimming of fish larvae determines connectivity of fish populations on the Great Barrier Reef. Naturwissenschaften 84: 262-268

Zapata FA, Herron PA (2002) Pelagic larval duration and geographic distribution of tropical eastern Pacific snappers (Pisces: Lutjanidae). Mar Ecol Prog Ser 230:295-300

Submitted: February 27, 2004; Accepted: July 15, 2004

Proofs received from author(s): December 27, 2004 